\title{
The psychosocial determinants of the intention to test for HIV among young men in KwaZulu-Natal province, South Africa
}

Citation for published version (APA):

Manyaapelo, T., Ruiter, R. A. C., Sifunda, S., Nyembezi, A., van den Borne, B., \& Reddy, P. (2021). The psychosocial determinants of the intention to test for HIV among young men in KwaZulu-Natal province, South Africa. AJAR-African Journal of AIDS Research, 20(1), 42-52. https://doi.org/10.2989/16085906.2020.1861034

Document status and date:

Published: 25/02/2021

DOI:

10.2989/16085906.2020.1861034

Document Version:

Publisher's PDF, also known as Version of record

\section{Document license:}

Taverne

Please check the document version of this publication:

- A submitted manuscript is the version of the article upon submission and before peer-review. There can be important differences between the submitted version and the official published version of record.

People interested in the research are advised to contact the author for the final version of the publication, or visit the DOI to the publisher's website.

- The final author version and the galley proof are versions of the publication after peer review.

- The final published version features the final layout of the paper including the volume, issue and page numbers.

Link to publication

\footnotetext{
General rights rights.

- You may freely distribute the URL identifying the publication in the public portal. please follow below link for the End User Agreement:

www.umlib.nl/taverne-license

Take down policy

If you believe that this document breaches copyright please contact us at:

repository@maastrichtuniversity.nl

providing details and we will investigate your claim.
}

Copyright and moral rights for the publications made accessible in the public portal are retained by the authors and/or other copyright owners and it is a condition of accessing publications that users recognise and abide by the legal requirements associated with these

- Users may download and print one copy of any publication from the public portal for the purpose of private study or research.

- You may not further distribute the material or use it for any profit-making activity or commercial gain

If the publication is distributed under the terms of Article $25 \mathrm{fa}$ of the Dutch Copyright Act, indicated by the "Taverne" license above, 


\section{The psychosocial determinants of the intention to test for HIV among young men in KwaZulu-Natal province, South Africa}

Thabang Manyaapelo, Robert AC Ruiter, Sibusiso Sifunda, Anam Nyembezi, Bart van den Borne \& Priscilla Reddy

To cite this article: Thabang Manyaapelo, Robert AC Ruiter, Sibusiso Sifunda, Anam Nyembezi, Bart van den Borne \& Priscilla Reddy (2021) The psychosocial determinants of the intention to test for HIV among young men in KwaZulu-Natal province, South Africa, African Journal of AIDS Research, 20:1, 42-52, DOI: 10.2989/16085906.2020.1861034

To link to this article: https://doi.org/10.2989/16085906.2020.1861034

曲 Published online: 25 Feb 2021.

Submit your article to this journal $2 \pi$

Џll Article views: 63

Q View related articles $\longleftarrow$

View Crossmark data $₫$ 


\title{
Research Article
}

\section{The psychosocial determinants of the intention to test for HIV among young men in KwaZulu-Natal province, South Africa}

\author{
Thabang Manyaapelo ${ }^{*}(\mathbb{D})$, Robert AC Ruiter ${ }^{2}(\mathbb{D})$, Sibusiso Sifunda ${ }^{1}(\mathbb{D})$, Anam Nyembezi ${ }^{3}(\mathbb{D})$, Bart van den Borne ${ }^{4} \&$ \\ Priscilla Reddy ${ }^{1}$ (iD
}

${ }^{1}$ Human and Social Capabilities Programme, Human Sciences Research Council, Pretoria, South Africa

${ }^{2}$ Department of Work \& Social Psychology, Maastricht University, Maastricht, The Netherlands

${ }^{3}$ School of Public Health, University of the Western Cape, Bellville, South Africa

${ }^{4}$ Department of Health Education and Health Promotion, Maastricht University, Maastricht, The Netherlands

*Correspondence: tmanyaapelo@hsrc.ac.za

\begin{abstract}
Background: Voluntary counselling and testing is one of the effective prevention strategies against the HIVIAIDS epidemic. This study investigated the psychosocial determinants of the intention to be tested for HIV among young men in South Africa's KwaZulu-Natal province using the theory of planned behaviour as the guiding framework. Method: A facilitator-administered questionnaire was used to collect data among $\mathbf{3 5 0}$ isiZulu-speaking men between the ages of 18 and 35.

Results: Results show that $\mathbf{2 4 \%}$ reported ever having tested. Intention to test showed strong positive correlations with subjective norm to test $(r=0.67)$, intention to use condoms $(r=0.65)$, intention to reduce alcohol use $(r=0.60)$, subjective norm to reduce alcohol use $(r=0.54)$, and subjective norm to use condoms $(r=0.51)$. For multiple regression, attitude, subjective norm and perceived behavioural control explained $43 \%$ of the variance in intention to test, with subjective norm and perceived behavioural control making significant unique contributions. An additional $12 \%$ of the variance was explained by intention to reduce alcohol and drug use, and use condoms.

Conclusion: Behavioural interventions to encourage HIV testing among men should target normative and control beliefs but also other risky behaviours (e.g. alcohol abuse and condom use) as reductions in these behaviours appear to be positively associated with motivation to undergo HIV testing.
\end{abstract}

Keywords: antiretroviral therapy (ART), HIV testing, psychosocial determinants, theory of planned behaviour, voluntary counselling and testing (VCT)

\section{Introduction}

The World Health Organization (WHO) and UNAIDS (Joint United Nations Programme on HIVIAIDS) have adopted voluntary counselling and testing (VCT) as one of the prevention strategies to curb the human immunodeficiency virus and acquired immunodeficiency syndrome (HIVIAIDS) epidemic. For this strategy to be effective, the broader aims of VCT will have to be achieved. These aims include a series of interdependent processes which start when people are identified through quality testing services. This is followed up by linking those who test positive to treatment, support services and scaling up high-impact interventions to reduce HIV transmission and related morbidity and mortality (WHO, 2016). There have been efforts over the years to expand HIV testing to as many people as possible in line with the UNAIDS 90-90-90 targets for the year 2020 (UNAIDS, 2014). This goal is that $90 \%$ of people living with HIV know their status, that $90 \%$ of those who know their status are on treatment, and that $90 \%$ of those on treatment have suppressed viral loads.

VCT is particularly important since South Africa has one of the highest prevalence rates at $20.6 \%$ among the age group 15-49 years and even higher rates of up to $27 \%$ in the study province, KwaZulu-Natal (KZN) (Simbayi et al., 2019). Of the estimated 37.9 million people living with HIV globally, only 24.5 million people are on antiretroviral therapy (ART) (UNAIDS, 2019). South Africa has made significant strides in this regard by placing $62 \%$ of the people living with HIV on ART and, most notably, by reducing the annual transmission rate from 410000 people in 2011 to approximately 240000 people in 2018 (UNAIDS, 2018). Despite these achievements of placing people living with HIV on lifesaving treatment, there still remains a number of challenges related to VCT. VCT can be initiated by clients or providers, and is usually initiated and administered at health testing facilities or in the community (Witzel et al., 2017). Some of the challenges or barriers that can impede the uptake of VCT 
are structural, while others can be classified as personal or psychosocial.

The structural barriers are associated with conventional HIV testing facilities and these include but are not limited to the distance from the facility, confidentiality concerns, long waiting times, and negative evaluations of the health care staff (Sharma et al., 2015; Mohlabane et al., 2016). There has been a recent call to support community-based HIV testing over testing at health care facilities (Suthar et al., 2013; Witzel et al., 2017). Community testing facilities have been found to be versatile because they can be provided in places such as homes, workplaces or by mobile services, therefore reaching more people (Sharma et al., 2015). It has been reported that when it comes to accessing health care in general, men do not participate as readily as women do. One of the reasons given is that women are more sensitised to health care due to their need for reproductive and antenatal services (Van Heerden et al., 2015). Other factors which contribute to low uptake of VCT by men include the societal expectations for men to be more resilient and fearless (Nyamhanga et al., 2013; Mburu et al., 2014). Therefore, men present to health facilities much later in their illness as opposed to earlier when a more favourable outcome was possible (Chikovore et al., 2016). In another study where HIV testing facilities were purposefully located closer to public transportation, and where opening hours were extended and facilities were converted to men-only centres, it was found that the total number of men who attended per month increased (Cornell et al., 2015). Therefore, the socio-economic conditions of men should be taken into account when investigating their reluctance to take up VCT (Zhang et al., 2020). The psychosocial factors that contribute to the low uptake of HIV testing include the fear of testing positive, low perceived risk of infection, and the fear of being stigmatised should the test be positive (Meiberg et al., 2008; Scott-Sheldon et al., 2013; Blondell et al., 2015; De Jesus et al., 2015; Sharma et al., 2015). An understanding of both the structural (including socio-economic) and psychosocial aspects of HIV testing is important for developing future behavioural interventions.

Although previous research has reported extensively on the structural factors associated with the poor uptake of VCT services in general, there is a paucity of theory-informed studies investigating the behavioural determinants of the uptake of VCT services. Moreover, even fewer studies utilise the theory of planned behaviour (TPB), which, so far, has been the most commonly used social-cognitive framework to identify psychosocial determinants of health behaviour (Conner \& Sparks, 2005; Conner \& Norman, 2015). The theory of planned behaviour is an extension of the theory of reasoned action and the more recent formulation is referred to as the reasoned action approach (Fishbein \& Ajzen, 2010). TPB posits that behavioural intention is determined by three evaluative constructs: attitude, subjective norm, and perceived behavioural control. Attitude represents a person's overall evaluation of the anticipated outcomes (favourable versus unfavourable) of the behaviour. Subjective norm is the perceived social pressure to engage or not engage in behaviour. Perceived behavioural control is people's perceptions of their ability to perform a given behaviour (Ajzen, 1991).
Studies investigating the theory of planned behaviour have shown that although cognitive constructs do influence the intention to be tested for HIV, they do so in a variety of combinations across the different studies. In a study investigating the intention to undergo testing for HIV among a population of women attending antenatal counselling, it was found that both attitude and subjective norm contributed significantly to explain the variance in intention for both women and their male partners (Mirkuzie et al., 2011). Attitude and perceived behavioural control showed a significant contribution in two African studies. In one study investigating married couples in Tanzania, perceived behavioural control showed the largest influence on HIV testing motivation (Mtenga et al., 2015). In the second study among Nigerian university students, TPB variables explained $35 \%$ of the variance in HIV testing intention and perceived risk contributed an additional $2 \%$ to the final model (Olabode, 2017). Perceived behavioural control is also reported to be the strongest predictor in another study among teachers (male and female) in Tanzania (Kakoko et al., 2006), while for teachers in Ethiopia, subjective norm and attitude contributed more to the intention to be tested for HIV (Omer \& Haidar, 2010). Another study in Ethiopia among health professionals (male and female) found that subjective norm and attitude were the most important contributors to the variance in the intention to test for HIV (Abamecha et al., 2013). In a more recent study among women engaging in compensated dating in Hong Kong, the intention to undergo HIV testing was significantly predicted by attitudes, subjective norms, perceived behavioural control, ever having been tested for HIV and perceived discrimination from health care workers, explaining $42 \%$ of the variance in intention (Mo et al., 2019). The overall variance explained by these studies ranges between $9.2 \%$ and $42 \%$. These previous studies demonstrate how the predictive capabilities of TPB vary in different contexts.

In this study, we report on the baseline dataset collected in the development and adaptation of a life-skills behavioural intervention among young men in $\mathrm{KZN}$. The study aimed to investigate the psychosocial determinants of the intention to be tested for HIV using the theory of planned behaviour as the guiding framework. To be tested for HIV, to test for HIV and to undergo HIV testing are used interchangeably in this article to refer to the serological test that determines whether a person is HIV positive or HIV negative. We also included a broader range of factors and other kinds of behaviour that could serve as possible determinants of the intention to test for HIV. Demographic determinants such as age and level of education are significantly associated with acceptance of VCT (Johnston et al., 2010).

Studies have also shown that having high HIV knowledge does not necessarily mean that people will test for HIV (Oppong Asante, 2013), but those who have undergone HIV testing are likely to be more knowledgeable about HIV transmission than those who have not tested (Haile et al., 2007) and, more importantly, those who have tested show a reduction in risky sexual behaviour (Scott-Sheldon et al., 2013). Previous studies have also shown that alcohol and drug use have a negative impact on the decision to use condoms (Castilla et al., 1999; Rehm et al., 2012). Furthermore, the decision to use condoms is associated with 
the number of sexual partners a person has, with men who reported having multiple sexual partnerships more likely to have used a condom at last sex (Onoya et al., 2015).

Interestingly, never having been tested for HIV has been reported to be a predictor of multiple sexual partnerships (Mlambo et al., 2018). Risky sexual behaviours should, therefore, not be examined in isolation, but should be studied in terms of how they influence one another. Additionally, masculinity norm traits have been shown previously to have an impact on men's decisions to access health care, including HIV testing (Sileo et al., 2018). It is reported that men fear that a positive result will affect their status as a provider and limit their successes with women (Fleming et al., 2016; Sileo et al., 2018). This study sought to better understand the intention for undergoing HIV testing by also examining the determinants of other risky kinds of behaviour such as condoms use, alcohol and drug use and behaving like a responsible man.

We introduced variables relating to alcohol and marijuana use because of the general negative influence they have on healthy decision-making (Pattij et al., 2008; Charnigo et al., 2013). The concept of responsible manhood was introduced in an attempt to extend the predictive capabilities of the theory of planned behaviour. The communities where the young men were drawn from were largely traditional and still practised customs such as lobola or bride price, which were recognised as an act of responsibility wherein young men are expected through their own efforts to gather resources that will allow them a future marriage. By extension, there is also an expectation of the male being responsible for maintaining their future household (Hunter, 2006). This act is seen as responsible male behaviour, whereas impregnating a young woman whom a young man is not married to is frowned upon and highly discouraged as irresponsible behaviour (Hunter, 2006).

We then proceeded to construct a new variable derived from concepts of supportive male roles together with discouraging hurtful behaviour in intimate relationship partners. The rationale for introducing this concept of responsible manhood was to see if the idea or act of being a responsible man could have any association with the intention to be tested for HIV. Additionally, we conducted a preliminary survey in these communities which found that alcohol and marijuana use were perceived to be high among young people in the community. This, therefore, reinforced our decision to include measures of alcohol and drug use. In summary, the decision to be tested for HIV is influenced by other behaviours such as condom use, substance use, multiple sexual partnerships, as well as other factors such as HIV knowledge and masculinity norms. The objectives of this study were to investigate the psychosocial determinants of the intention to be tested for HIV among young men in $\mathrm{KZN}$, by using the theory of planned behaviour as the guiding framework.

\section{Materials and methods}

\section{Study design}

This article reports on the baseline data which forms part of a larger dataset collected in the development and testing of a health-behaviour intervention targeted at young men in
$K Z N$. The research design for the larger dataset study was in two parts, a randomised pre-test/post-test control group design for the one part (peri-urban site) and a pre-test/ post-test without a control group for the other part (rural site) (Manyaapelo et al., 2019). The overall intervention sought to encourage a reduction in risky sexual behaviour such as not using condoms, not being tested for HIV, having multiple sexual partners, engaging in sexual activities when under the influence of alcohol and illicit drugs. Lastly, the intervention attempted to encourage young men to play more supportive positive male roles in their respective communities. The study received full ethical clearance from the South African Medical Association Research Ethics Committee (SAMAREC - Protocol MRC 1-09), which works according to the guideline of the Helsinki Declaration on ethical aspects in human experimentation. The research team also sought and received permission from the local municipal offices and the traditional leadership in the area concerned. Participants gave written informed consent to participate in the study.

\section{Participants and study setting}

The study was conducted in KZN on the north-eastern coast of South Africa. It is the second most populated province and home to 10.8 million people, with $89.4 \%$ being black African, $7.1 \%$ Indian/Asian, $2.4 \%$ white, and $1.0 \%$ coloured, according to the South African population classifications (Statistics South Africa, 2016). The inclusion criteria for the sample were: males who self-identified as heterosexual between the ages of 18 and 35, who were isizuluspeaking, resided in the area and indicated availability for a follow-up at six months post intervention. Globally, youth are described as the population between the ages of 15 and 24, according to the United Nations General Assembly (United Nations, 2005) but in South Africa, youth is defined as between 18 and 35 years old. This extension to 35 was legislated through the National Youth Commission Act of 1996 to include older youth who had been disadvantaged by their role in the struggle against apartheid (Republic of South Africa, 1996). This study adopted the South African definition of youth. The research participants were recruited from multiple community sites such as schools, churches, and community organisations. Participation in the study was voluntary for all participants who met the inclusion criteria and were able to participate during the times allocated.

Researchers provided transport (where necessary) since the research venue was very far for some participants and a provision for refreshments was made because the sessions were approximately three hours long. The recruitment drive included a well-publicised initiative of talks about the study aims at community meetings, local churches and sports tournaments organised specifically for this purpose. At the peri-urban site, the research team was also hosted at a local community radio station to answer questions the community had about the study. This recruitment drive continued for nearly 12 months before the study commenced. Site A is a peri-urban locality roughly $30 \mathrm{~km}$ from Durban with a majority black African population, while Site B is rural and approximately $250 \mathrm{~km}$ from Durban, also with a majority black African population. 


\section{Study instruments}

Data was collected in 2010 and 2011 through a facilitatoradministered questionnaire. This questionnaire was adapted from a previous study among male prison inmates in KZN and Mpumalanga provinces (Sifunda et al., 2006; 2008). Additionally, the contents for the questionnaire were derived from a literature review on the topic, as well as focus group interviews among the study group. The questionnaire was divided into three sections, where the first section measured the demographic profile of the population in terms of age, level of education, level of income, and whether participants were involved in sexual relationships or not. The second section examined the participants' sexual risk behaviour in terms of having been tested for HIV, the number of sexual partners, and current substance use behaviour concerning alcohol and marijuana use. The last section focused on the psychosocial measures using the theory of planned behaviour, where attitude, subjective norm, perceived behavioural control, and intention were measured for each type of behaviour. The questionnaire was developed in English, translated into isiZulu and then translated back into English to ensure construct and face validity. The research assistants and project managers, who were from the same background as the research participants, were responsible for the translation process. The translations were done during a workshop attended by all the research assistants, project managers and some of the co-authors. Consensus was reached for the correct use of language for all research tools.

\section{Measures and scale construction \\ HIV knowledge}

Ten single items measured knowledge of HIV using: 1 = True, $2=$ False, and $3=1$ don't know response options. (e.g. The HIV virus can be passed from a pregnant mother, if she is infected with HIV, to her unborn child). The responses were dichotomised as $1=$ True and $0=$ False, or I don't know).

\section{Multiple partners}

Sexual behaviour was measured by asking about the number of sexual partners the participant had engaged in sex with in the past six months. A four-point scale was used with answering options of: $0=$ not sexually active; $1=$ one sexual partner; 2 = between two and five sexual partners, $3=$ between six and ten sexual partners, and $4=$ ten or more sexual partners.

\section{Alcohol and marijuana use}

Two single items assessed the frequency of alcohol and marijuana use in the past six months, respectively, using a five-point scale with options of $1=$ never $(0$ days $), 2=$ rarely (one to two days), $3=$ sometimes (three to nine days), $4=$ often (10 to 19 days), and $5=$ very often ( 20 days or more).

\section{Psychosocial correlates}

The variables of attitude, subjective norm and intention toward being tested for HIV, attitude, subjective norm and intention towards condom use, attitude, subjective norm and intention towards reducing alcohol and drug use were measured using a scale of 1 to 5 with answering options of: 1 = strongly/fully disagree, $2=$ disagree, $3=$ unsure, $4=$ agree, and $5=$ strongly/fully agree for attitude, subjective norm and intention, while perceived behavioural control was measured using a scale of 1 to 5 with options of: $1=$ very confident; 2 = confident, 3 = unsure; $4=$ not confident, and $5=$ not confident at all. Table 1 provides an overview of the psychosocial correlates that were measured, including the number of items, sample items, minimum and maximum scores, mean score and standard deviation, and the Cronbach's alpha (three or more items) or Pearson's $r$ (two items) as a measure of the internal consistency of grouped items.

\section{Analysis}

Statistical analysis was done using SPSS Version 24. Bivariate correlations analysis was used to assess associations between study measures. Hierarchical linear regression models were then used to determine the unique contribution the study measures made to explaining the overall variance in the intention to test for HIV in the coming three months. The regression was done in a six-step process starting with the more proximal predictors and ending with the more distal predictors to check for additional variance explained. In step 1, the outcome variable, intention to test for HIV, is tested against the most proximal predictors, which include attitude, subjective norm and perceived behavioural control to test for HIV. In step 2, intention towards condom use, intention towards reducing alcohol and marijuana use, and intention towards responsible manhood were added. Step 3 added attitudes, subjective norm and perceived behavioural control towards the behaviour, condom use and reduction of alcohol and drug use. Step 4 added the HIV knowledge. Step 5 added attitude, subjective norm, and perceived behavioural control towards responsible manhood. Finally, the demographic variables (age, level of education) and behavioural variables (past substance use and sexual behaviour) were added in step 6 .

\section{Results}

\section{Sociodemographic profile of the participants}

A total of 575 young men completed the baseline questionnaire, of whom $350(60.9 \%)$ responded "yes" to "having had one or more sexual partners in the past six months". A sexual partner was defined as any person with whom the participant had either vaginal or anal sex.

Three hundred and fifty young men were included in this analysis. Their ages ranged from 18 to 35 , with the majority $(64.9 \%)$ between the ages of 18 and 20 (Table 2). The level of education for this sample varied from primary education to tertiary education, with $40 \%(n=143)$ of the sample having a grade 12 (high school graduation) or higher qualification. Almost all participants reported being unemployed (96.2\%). Most participants lived with at least one parent or with a relative.

\section{Sexual behaviour and substance use}

HIV knowledge was substantial with $88.4 \%$ who knew that they could contract HIV if they had sexual intercourse without using a condom and $78 \%$ who knew that even if a person looks healthy, he or she could still be infected with HIV. Just 
Table 1: Overview of scale measures with examples

Measures and example items

$\begin{array}{cccc}\text { Number } & \text { Minimum } & \text { Maximum } & \text { Mean } \\ \text { of items } & \text { score } & \text { score } & \text { score }\end{array}$

score score

Attitude towards testing for HIV at a VCT clinic in the next three months

- Getting tested for HIV at a VCT clinic in the next three months is something that is good

Subjective norm towards testing for HIV at a VCT clinic in the next three months

- Most people who are important to me think that getting tested for HIV at a VCT clinic in the next three months is a good thing

Perceived behavioural control testing for HIV at a VCT clinic in the next three months

- For me to test for HIV at a VCT clinic in the next three months is possible Intention towards testing for HIV at a VCT clinic in the next three months

- I intend to test for HIV at a VCT clinic in the next three months

Attitude towards using a condom consistently for every sexual encounter in the next three months

- Using a condom consistently for every sexual encounter in the next three months is something that is good

Subjective norm towards using a condom consistently for every sexual encounter in the next three months

- Most people who are important to me think that using a condom for every sexual encounter consistently in the next three months is a good thing

Perceived behavioural control towards using a condom consistently for every sexual encounter in the next three months

- For me to use a condom consistently for every sexual encounter in the next three months is possible

Intention towards using a condom consistently for every sexual encounter in the next three months

- I intend to use a condom consistently for every sexual encounter in the next three months

Attitude towards reducing overall alcohol and drug intake

- Reducing overall drug and alcohol intake to only one day a week in the next three months is something that is wise

Subjective norm towards reducing overall alcohol and drug intake

- Most people who are important to me think that reducing overall drug and alcohol intake to only one day a week in the next three months is a good thing

Perceived behavioural control towards reducing overall alcohol and drug intake

- For me to reduce overall drug and alcohol intake to only one day a week in the next three months is possible

Intention towards reducing overall alcohol and drug intake

- I intend to reduce overall drug and alcohol intake to only one day a week in the next three months

Attitude towards behaving as a responsible man

- A responsible man is someone who has to discipline his wife/partner when necessary using physical force

Subjective norm towards behaving as a responsible man

- Most of your community members think that a responsible man is someone who has to discipline his wife/partner when necessary using physical force.

Perceived behavioural control towards behaving as a responsible man

- How confident are you that you will be able to look after your partner's well-being?

Intention towards behaving as a responsible man

- I intend to discipline my wife/partner when necessary using physical force in the next three months

\begin{tabular}{|c|c|c|c|c|c|}
\hline 6 & 1 & 5 & 4.4 & 0.80 & 0.80 \\
\hline 5 & 1 & 5 & 4.0 & 1.0 & 0.88 \\
\hline 4 & 1 & 5 & 4.4 & 0.85 & 0.76 \\
\hline 6 & 1 & 5 & 4.0 & 1.0 & 0.92 \\
\hline 5 & 1 & 5 & 4.5 & 0.73 & 0.81 \\
\hline 5 & 1 & 5 & 3.8 & 1.1 & 0.88 \\
\hline 3 & 1 & 5 & 4.4 & 0.83 & 0.70 \\
\hline 6 & 1 & 5 & 4.1 & 1.0 & 0.92 \\
\hline 6 & 1 & 5 & 4.3 & 0.97 & 0.84 \\
\hline 5 & 1 & 5 & 3.8 & 0.99 & 0.84 \\
\hline 4 & 1 & 5 & 4.2 & 0.83 & 0.75 \\
\hline 7 & 1 & 5 & 4.1 & 1.0 & 0.93 \\
\hline 2 & 1 & 5 & 3.4 & 0.70 & 0.59 \\
\hline 2 & 1 & 5 & 3.1 & 0.64 & 0.73 \\
\hline 2 & 1 & 5 & 2.1 & 0.81 & 0.42 \\
\hline 1 & 1 & 5 & 3.1 & 0.87 & - \\
\hline
\end{tabular}


Table 2: Sociodemographic details of the participants $(N=350)$

\begin{tabular}{lrr}
\hline Characteristic & Frequency & Percentage \\
\hline Age (years) & 226 & \\
$18-20$ & 85 & $24.9 \%$ \\
$21-25$ & 30 & $8.6 \%$ \\
$26-30$ & 7 & $2.0 \%$ \\
$31-35$ & 1 & $0.3 \%$ \\
Level of education & 189 & $54.3 \%$ \\
$\quad$ Primary school & 100 & $30.0 \%$ \\
High school & 43 & $12.3 \%$ \\
Matric & & \\
Tertiary & 12 & \\
Employment status & 335 & $96.4 \%$ \\
$\quad$ Employed & & \\
$\quad$ Not employed & 34 & $10.5 \%$ \\
Living arrangements & 150 & $43.1 \%$ \\
Living on own & & \\
Living with others & 80 & $24.0 \%$ \\
HIV status & 268 & $77.0 \%$ \\
$\quad$ Have previously tested for HIV & & \\
Have previously not tested for HIV &
\end{tabular}

under a third knew that HIV could be passed from a pregnant mother to the unborn child. Only $24 \%$ of the participants answered "yes" to the question, "Have you ever visited a VCT clinic and got tested for HIV?". More than three quarters were knowledgeable about the use of condoms, with $78.8 \%$ and $81.3 \%$ responding that condoms can prevent the spread of HIV and can also prevent pregnancies, respectively. Just over three quarters reported having used alcohol in their lifetime and $38.9 \%$ reported having used marijuana. A total of $36.3 \%$ of the participants had used both alcohol and marijuana. About $73 \%$ of the participants reported having had multiple concurrent sexual partnerships.

\section{Predictors of intention to test for HIV in three months}

Table 3 presents both the correlation and the regression results for the intention to be tested for HIV outcome variable. This outcome variable showed strong positive correlations with the subjective norm to be tested for HIV $(r=0.67)$, the intention to use condoms $(r=0.65)$, the intention to reduce alcohol and drug use $(r=0.60)$, the subjective norm to reduce alcohol and drug use $(r=0.54)$, and the subjective norm to use condoms $(r=0.51)$. Moderate positive correlations were shown with perceived behavioural control to be tested for HIV $(r=0.30)$ and attitude towards being tested for HIV $(r=0.28)$. Weak but still positive correlations were shown with perceived behavioural control to use condoms $(r=0.22)$, attitude to reduce alcohol and drug use $(r=0.21)$, perceived behavioural control to reduce alcohol and drug use $(r=0.19)$, attitude to use condoms $(r=0.18)$, perceived behavioural control towards responsible manhood $(r=0.15)$, knowledge of HIV $(r=0.13)$, intention towards responsible manhood $(r=0.12)$, and, lastly, attitude towards responsible manhood $(r=0.11)$.

The stepwise multiple regression analysis showed that, in the first step, attitude, subjective norm and perceived behavioural control to be tested for HIV explained $43 \%$ of the variance in the intention to be tested for HIV, showing significant unique contributions of subjective norm and perceived behavioural control. The second step introduced the intention to reduce alcohol and drug use as well as the intention to use condoms and intention towards responsible manhood. These correlates explained an additional $12 \%$ of the variance in the intention to be tested for HIV, with significant contributions from intention to use condoms and intention to reduce alcohol and drug use. From the third to the sixth steps, no significant additional variance was found. In these steps, we introduced the cognitions of attitude, subjective norm and perceived behavioural control towards three kinds of behaviour (reduction of alcohol and drug use, condom use and responsible manhood). We also introduced knowledge of HIV, demographic and past behaviour variables. The final model explained $55 \%$ of the variance in the intention to be tested for HIV in the following three months with unique significant contributions of the subjective norm toward being tested for HIV, perceived behavioural control towards being tested for HIV, intention towards condom use, and intention towards reduction of alcohol and drug use.

\section{Discussion}

The objective of our study was to examine the psychosocial determinants of the intention to undergo testing for HIV among young men in $\mathrm{KZN}$ using the theory of planned behaviour as our framework. We also introduced variables related to alcohol and marijuana use as well as variables assessing responsible manhood in an attempt to assess their influence on the intention to be tested for HIV. The regression analysis shows that the most proximal cognitions (attitude, subjective norm and perceived behavioural control to be tested for HIV) explained $43 \%$ of the variance in the intention to be tested for HIV. Subjective norm and perceived behavioural control made the most significant contributions to this model. These findings are comparable to previous studies, which reported subjective norm and perceived behavioural control as having had significant contributions in explaining the variance (Kakoko et al., 2006; Omer \& Haidar, 2010; Abamecha et al., 2013; Mtenga et al., 2015). The total explained variance in these studies ranges between $9 \%$ and $41 \%$, the upper end being the most comparable to the present study. It should be highlighted that in developing our measurement tools of the TPB constructs, we closely followed the guidelines outlined for the construction of measures of TPB variables (Ajzen, 2006). In particular, we took notice of the compatibility principle and thus ensured that our measures of attitude, subjective norm and perceived behavioural control were specific to the intention in question (Ajzen \& Fishbein, 2005).

The results suggest that our participants' intention to be tested for HIV was strongly influenced by the opinions of people whom our participants held in high regard. Additionally, the strong influence of perceived behavioural control suggests that if the behavioural intervention was to strengthen their feelings of personal control on their decision to take an HIV test, it would strengthen the motivation to do so. The ability of intention to correctly predict behaviour is rendered less effective when actual control is absent (Ajzen \& Fishbein, 2005). Participants in the current study have perceptions of control, which could be attributed to the numerous, widely accessible free testing facilities provided 


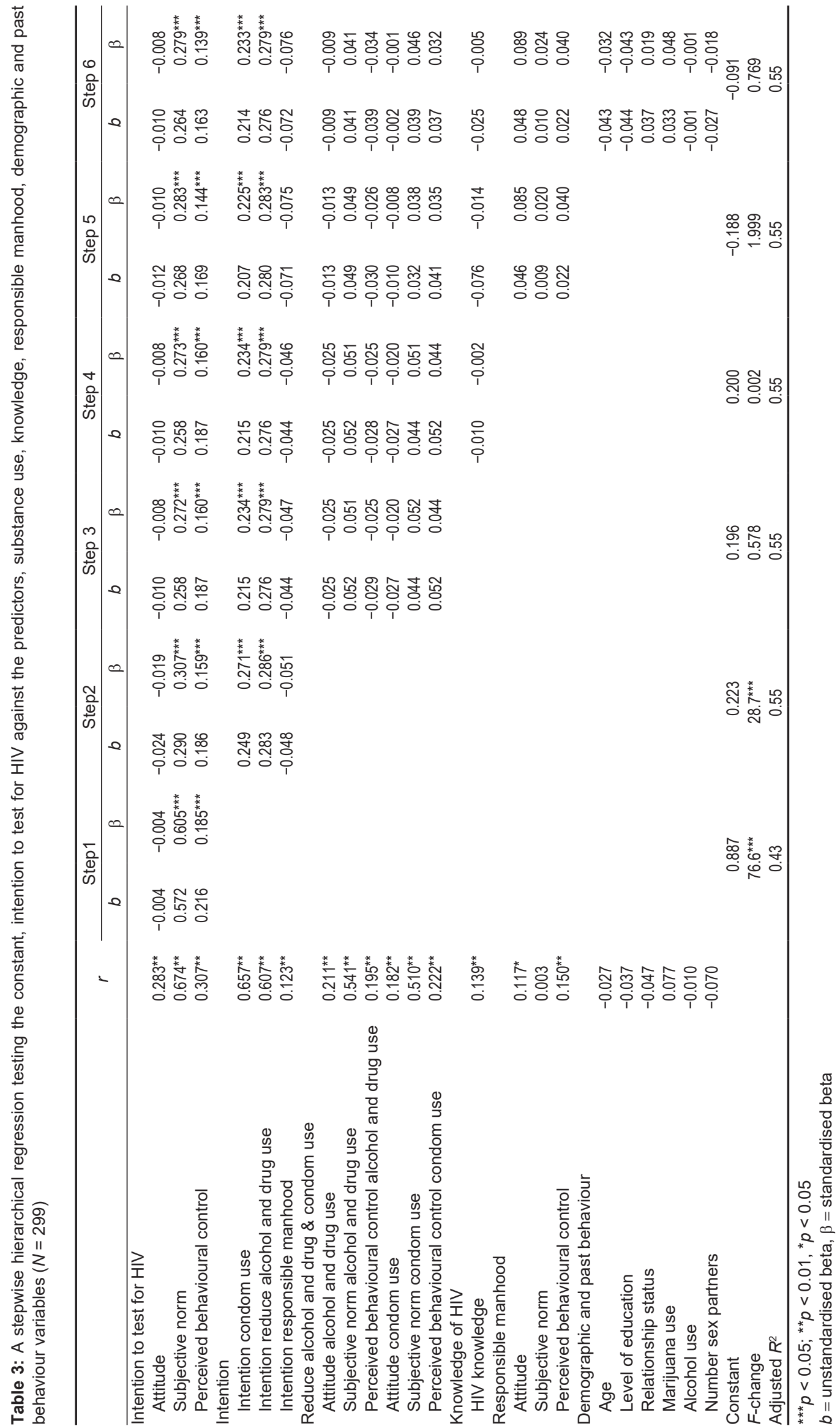


by the government. Having these facilities addresses part of the structural barriers to getting tested and, therefore, may influence perceptions of having control in the decision to test or not.

Previous research in South Africa reported that the major barriers to HIV testing were more personal than structural (Mohlabane et al., 2016; Weihs \& Meyer-Weitz, 2016) and this was also true for Europe (Deblonde et al., 2010). These barriers included being scared of what people might say, fear regarding lack of confidentiality, fear of getting an HIV-positive result, fear of being stigmatised or discriminated against if one tested positive, embarrassment of divulging personal information to health workers and low levels of perceived HIV risk. Additionally, high levels of psychological distress, including depression and anxiety, have been shown in people seeking to get tested, thereby negatively affecting both the intention to test and adherence to ART in the event of an HIV-positive test result. (Saal \& Kagee, 2011; Nothling \& Kagee, 2013; Kagee et al., 2017). Factors such as being scared of what people may say and fear of being stigmatised speak directly to the findings of the present study concerning the normative beliefs of a given community. In other words, what is perceived to be normal in a community can influence how members of that community ultimately behave. For example, if positive social evaluations such as testing for HIV were to be reinforced and promoted, while the stigma against testing was rejected by the same community, then this may encourage more people to test. It is also interesting to note that these normative beliefs do not have to be overwhelmingly convincing because it has been shown that even weakly held beliefs were sufficient to cause action (Amjad \& Wood, 2009).

In the second step of the multiple regression, we introduced the variables: intention to reduce alcohol and drug use, the intention to use condoms, and the intention towards responsible manhood These variables contributed an additional $12 \%$ to the variance $(p \leq 0.01)$ in the intention to be tested for HIV, with significant contributions by intention to use condoms and the intention to reduce alcohol and drug use. Therefore, when developing behaviour change interventions, researchers should not only target the specific behaviour in question, but investigate broadly to find out if there are any "low hanging fruit" (i.e. related kinds of risk behaviour) that could also be changed (Vigen \& Mazur-Stommen, 2012). A positive change in the related risky behaviour may in turn have a positive effect on the target behaviour.

The addition of the measures related to responsible manhood (attitude, subjective norm, perceived behavioural control), as well as measures of HIV knowledge, and indicators of social demography and past behaviour did not yield any significant change in the variance of the intention to be tested for HIV. It is not surprising that HIV knowledge and past behaviour did not yield any significant association. Research shows that even though high levels of HIV knowledge and reduced HIV-related stigma are positively correlated to having had an HIV test in the past, they do not have a significant relationship with intention to be tested for HIV in the future (Okumu et al., 2017). Previous studies further show that past behaviour does not necessarily predict future behaviour because factors such as the type of behaviour and the context in which the behaviour is performed are pivotal to the prediction (Ouellette \& Wood, 1998). The newly constructed variables attempting to assess responsible manhood showed significant but weak correlations for intention, perceived behavioural control and attitudes towards responsible manhood, but did not explain any additional variance in intention to get tested. These new constructs need to be investigated further because they help to explain the social and sexual contexts of the communities in question.

What is pivotal to understand is that getting tested for HIV should not be viewed in isolation, but as an action that is likely preceded by incidents of risky sexual behaviour. More importantly, sexual behaviour in itself is a result of complex emotional or biological processes. Therefore, to fully explain the psychosocial determinants of getting tested for HIV, we need to also understand risky sexual behaviour more deeply. Previous literature suggests that very few studies provide evidence for the validity of health behaviour theories in predicting sexual behaviour (Huebner \& Perry, 2015). More specifically, when looking at the theory of planned behaviour, issues such as the time gap between measurement of TPB variables and the subsequent behaviour, as well as measurement error in the assessment of predictors of intention, account for part of the variance in intention not explained by tested models (McEachan et al., 2011; Ajzen, 2015). Therefore, future studies should be mindful of some of the limitations of TPB so that, where appropriate, researchers carefully segment the target population under investigation. Doing this would enable better prediction capabilities of the tested models since socio-economic status and education, for example, have recently been shown to moderate between intention and behaviour, albeit in different contexts (Conner et al., 2017).

Another important aspect to consider is that the individual's behaviour is controlled by two processes. These are the deliberative processes, which are governed by the rational and conscious decision-making about any given action, and implicit processes, which are governed by spontaneous, non-conscious influences (Hagger, 2016). Some of the leading proponents of the social-cognitive approaches acknowledge that social-cognitive theories do not provide a comprehensive account for social behaviour (Doll \& Ajzen, 1992; Aarts \& Dijksterhuis, 2000). Future studies should, therefore, consider social-cognitive approaches that incorporate a dual process of investigating behaviour.

\section{Study limitations}

This cross-sectional study was conducted between the hours of 08:00 and 17:00 from Mondays to Fridays. This led to inadvertently sampling a larger number of unemployed men who were also substance users. This sampling bias affects the quality of the generalisability of the results. The concept of responsible manhood needs to be further developed and investigated in the African context to yield a better contribution to our understanding of its role in HIV transmission. The extension of TPB variables that are hypothesised to aid in the prediction capabilities needs to be carefully considered; for example, past behaviour directly associated with HIV testing should be included in future studies. 


\section{Conclusions}

This study was able to demonstrate the effectiveness of the theory of planned behaviour in explaining the intention to be tested for HIV in a sample of young men in KZN. The significant contributions of subjective norm and perceived behavioural control suggest that behavioural interventions should target normative beliefs as well as control beliefs regarding the intention to get tested. What is also highlighted is that participants who had the intention towards more positive behaviour such as condom use and reduction of alcohol and drug use also reported a stronger intention to test for HIV. This suggested that behavioural change interventions should also aim to target other closely related risky behaviour, which may be easier to change than the behaviour in question.

Acknowledgments - This research was funded by the Ford Foundation (1115-0668-0), and publication supported by the Human and Social Capabilities Research Programme, Human Sciences Research Council.

The authors thank the Ford Foundation, South African Medical Research Council, Human Sciences Research Council, the leadership structures of the communities involved, the community research assistants, the research coordinators, and most of all the study participants for their support and cooperation in this project. The authors also wish to thank the anonymous reviewers for their insightful comments which immensely strengthened this article. Lastly, we thank Antoinette Oosthuizen for copyediting work.

\section{ORCIDs}

Thabang Manyaapelo: https://orcid.org/0000-0002-5664-6295

Robert AC Ruiter: http://orcid.org/0000-0001-5017-3258

Sibusiso Sifunda: http://orcid.org/0000-0002-8766-7240

Anam Nyembezi: https://orcid.org/0000-0003-4799-405X

Priscilla Reddy: https://orcid.org/0000-0002-0432-9060

\section{References}

Aarts, H. \& Dijksterhuis, A. (2000). Habits as knowledge structures: Automaticity in goal-directed behavior. Journal of Personality and Social Psychology, 78(1), 53-63. https://doi. org/10.1037/0022-3514.78.1.53

Abamecha, F., Godesso, A. \& Girma, E. (2013). Intention to voluntary HIV counseling and testing (VCT) among health professionals in Jimma zone, Ethiopia: The theory of planned behavior (TPB) perspective. BMC Public Health, 13(1), 1-7. https://doi. org/10.1186/1471-2458-13-140

Ajzen, I. (1991). The theory of planned behavior. Orgnizational Behavior and Human Decision Processes, 50, 179-211. https://doi. org/10.1016/0749-5978(91)90020-T

Ajzen, I. (2006). Constructing a TpB questionnaire: Conceptual and methodological considerations.

Ajzen, I. (2015). The theory of planned behaviour is alive and well, and not ready to retire: a commentary on Sniehotta, Presseau, and Araújo-Soares. Health Psychology Review, 9(2), 131-137. https:// doi.org/10.1080/17437199.2014.883474

Ajzen, I. \& Fishbein, M. (2005). The influence of attitudes on behavior. The Journal of Social Psychology, 173-221. https://doi.org/10.1080 /00224545.1956.9921907
Amjad, N. \& Wood, A. M. (2009). Identifying and changing the normative beliefs about aggression which lead young Muslim adults to join extremist anti-semitic groups in Pakistan. Aggressive Behavior, 35(6), 514-519. https://doi.org/10.1002/ab.20325

Blondell, S. J., Kitter, B., Griffin, M. P., \& Durham, J. (2015). Barriers and facilitators to HIV testing in migrants in high-income countries: A systematic review. AIDS and Behavior, 19(11), 2012-2024. https:// doi.org/10.1007/s10461-015-1095-x

Castilla, J., Barrio, G., Belza, M. J., \& de la Fuente, L. (1999). Drug and alcohol consumption and sexual risk behaviour among young adults: Results from a national survey. Drug and alcohol dependence, 56(1), 47-53.

Charnigo, R., Noar, S. M., Garnett, C., Crosby, R., Palmgreen, P., \& Zimmerman, R. S. (2013). Sensation seeking and impulsivity: combined associations with risky sexual behavior in a large sample of young adults. Journal of Sex Research, 50(5), 480-488. https:// doi.org/10.1080/00224499.2011.652264

Chikovore, J., Gillespie, N., Mcgrath, N., \& Orne-Gliemann, J. (2016). Men, masculinity, and engagement with treatment as prevention in KwaZulu-Natal, South Africa. AIDS CAre, 28(Suppl 3), 74-82. https://doi.org/10.1080/09540121.2016.1178953.Men

Conner, M., McEachan, R., Lawton, R., \& Gardner, P. (2017). Applying the reasoned action approach to understanding health protection and health risk behaviors. Social Science and Medicine, 195(March), 140-148. https://doi.org/10.1016/j.socscimed.2017.10.022

Conner, M. \& Norman, P. (2015). Predicting and Changing Health Behaviour: Research and Practice with Social Cognition Models. Open University Press (McGraw Hill Education).

Conner, M. \& Sparks, P. (2005). Theory of planned behaviour and health behaviour. In Conner M, \& Norman P (Eds), Predicting health behaviour, (pp. 121-162). Open University Press.

Cornell, M., Cox, V., \& Wilkinson, L. (2015). Public health blindness towards men in HIV programmes in Africa. Tropical Medicine and International Health, 20(12), 1634-1635. https://doi.org/10.1111/ tmi. 12593

Deblonde, J., De Koker, P., Hamers, F. F., Fontaine, J., Luchters, S., \& Temmerman, M. (2010). Barriers to HIV testing in Europe: A systematic review. European Journal of Public Health, 20(4), 422-432. https://doi.org/10.1093/eurpub/ckp231

De Jesus, M., Carrete, C., Maine, C., \& Nalls, P. (2015). Attitudes, perceptions and behaviours towards HIV testing among AfricanAmerican and East African immigrant women in Washington, DC: Implications for targeted HIV testing promotion and communication strategies: Table 1. Sexually Transmitted Infections, 91(8), 569-575. https://doi.org/10.1136/sextrans-2014-051876

Doll, J. \& Ajzen, I. (1992). Accessibility and stability of predictors in the theory of planned behavior. Journal of Personality and Social Psychology, 63(5), 754-765. https://doi. org/10.1037/0022-3514.63.5.754

Fishbein, M. \& Ajzen, I. (2010). Predicting and changing behavior: The reasoned action approach. Psychology Press (Taylor \& Francis).

Fleming, P. J., Diclemente, R. J., \& Barrington, C. (2016). Masculinity and HIV: Dimensions of masculine norms that contribute to men's HIV-related sexual behaviors. Aids Behaviour, 20(4), 788-798. https://doi.org/10.1007/s11065-015-9294-9.Functional

Hagger, M. S. (2016). Non-conscious processes and dual-process theories in health psychology. Health Psychology Review, 10(4), 375-380. https://doi.org/10.1080/17437199.2016.1244647

Haile, B. J., Chambers, J. W., \& Garrison, J. L. (2007). Correlates of HIV knowledge and testing. Journal of Black Studies, 38(2), 194-208. https://doi.org/10.1177/0021934705285595

Huebner, D. M. \& Perry, N. S. (2015). Do behavioral scientists really understand HIV-related sexual risk behavior? A systematic review of longitudinal and experimental studies predicting sexual behavior. Archives of Sexual Behavior, 44(7), 1915-1936. https:// doi.org/10.1007/s10508-015-0482-8 
Hunter, M. (2006). Fathers without AMANDLA: Zulu-speaking men and fatherhood. In L. Richter \& R. Morrell (Eds), BABA: Men and Fatherhood in South Africa (pp. 99-107). HSRC Press.

Johnston, L., O'Bra, H., Chopra, M., Mathews, C., Townsend, L., Sabin, K., Tomlinson, M., \& Kendall, C. (2010). The associations of voluntary counseling and testing acceptance and the perceived likelihood of being HIV-infected among men with multiple sex partners in a South African township. AIDS and Behavior, 14(4), 922-931. https://doi.org/10.1007/s10461-008-9362-8

Kagee, A., Saal, W., \& Bantjes, J. (2017). Distress, depression and anxiety among persons seeking HIV testing. AIDS Care Psychological and Socio-Medical Aspects of AIDS/HIV, 29(3), 280-284. https://doi.org/10.1080/09540121.2016.1259453

Kakoko, D. C., Åstrøm, A. N., Lugoe, W. L., \& Lie, G. T. (2006). Predicting intended use of voluntary HIV counselling and testing services among Tanzanian teachers using the theory of planned behaviour. Social Science and Medicine, 63(4), 991-999. https:// doi.org/10.1016/j.socscimed.2006.02.016

Manyaapelo, T., Van den Borne, B., Ruiter, R. A. C., Sifunda, S., \& Reddy, P. (2019). Effectiveness of a health behavioural intervention aimed at reduction of risky sexual behaviour among young men in the KwaZulu-Natal province, South Africa. International Journal of Environmental Research and Public Health, 16(11), 1938. https:// doi.org/10.3390/ijerph16111938

Mburu, G., Ram, M., Siu, G., Bitira, D., Skovdal, M., \& Holland, P. (2014). Intersectionality of HIV stigma and masculinity in eastern Uganda: Implications for involving men in HIV programmes. BMC Public Health, 14, 1061. https://doi.org/10.1186/1471-2458-14-1061

McEachan, R. R. C., Conner, M., Taylor, N. J., \& Lawton, R. J. (2011). Prospective prediction of health-related behaviours with the theory of planned behaviour: A meta-analysis. Health Psychology Review, 5(2), 97-144. https://doi.org/10.1080/17437199.2010.521684

Meiberg, A. E., Bos, A. E. R., Onya, H. E., \& Schaalma, H. P. (2008). Fear of stigmatization as barriers to voluntary HIV counselling and testing in South Africa. East African Journal of Public Health, 5(2), 49-55.

Mirkuzie, A. H., Sisay, M. M., Moland, K. M., \& Astrøm, A. N. (2011). Applying the theory of planned behaviour to explain HIV testing in antenatal settings in Addis Ababa - a cohort study. BMC Health Services Research, 11(1), 196. https://doi. org/10.1186/1472-6963-11-196

Mlambo, M. G., Peltzer, K., \& Chirinda, W. (2018). Predictors of multiple concurrent and multiple sexual partnerships among male and female youth aged 18-24 in South Africa. Journal of Psychology in Africa, 26(2), 156-163. https://doi.org/10.1080/14330237.2016.1 163901

Mo, P. K. H., Lau, J. T. F., Xin, M., \& Fong, V. W. I. (2019). Understanding the barriers and factors to HIV testing intention of women engaging in compensated dating in Hong Kong: The application of the extended theory of planned behavior. PLOS ONE, 14(6), 1-13. https://doi.org/10.1371/journal.pone.0213920

Mohlabane, N., Tutshana, B., Peltzer, K., \& Mwisongo, A. (2016). Barriers and facilitators associated with HIV testing uptake in South African health facilities offering HIV counselling and testing. Health SA Gesondheid, 21, 86-95. https://doi.org/10.1016/j. hsag.2015.11.001

Mtenga, S. M., Exavery, A., Kakoko, D., \& Geubbels, E. (2015). Social cognitive determinants of HIV voluntary counselling and testing uptake among married individuals in Dar es Salaam Tanzania: Theory of planned behaviour (TPB). BMC Public Health, 15(October), 1-8. https://doi.org/10.1186/s12889-015-1545-4

Nothling, J. \& Kagee, A. (2013). Acceptability of routine HIV counselling and testing among a sample of South African students: Testing the health belief model. African Journal of AIDS Research, 12(3), 141-150. https://doi.org/10.2989/16085906.2013.863214
Nyamhanga, T. M., Muhondwa, E. P. Y., \& Shayo, R. (2013). Masculine attitudes of superiority deter men from accessing antiretroviral therapy in Dar es Salaam, Tanzania. Global Health Action, 6, 1-9. https://doi.org/10.3402/gha.v6i0.21812

Okumu, E., Jolly, D. H., Alston, L., Eley, N. T., Laws, M., \& MacQueen, K. M. (2017). Relationship between human immunodeficiency virus (HIV) knowledge, HIV-related stigma, and HIV testing among young black adults in a southeastern city. Frontiers in Public Health, 5(47), 1-7. https://doi.org/10.3389/fpubh.2017.00047

Olabode, A. (2017). The theory of planned behavior as a predictor of HIV testing intention. American Journal of Health Behaviour, 41(2), 147-151.

Omer, S. \& Haidar, J. (2010). Applicability of the theory of planned behavior in predicting intended use of Voluntary HIV counseling and testing services among teachers of Harari Region, Ethiopia. Ethiopian Journal of Health Development, 24(2), 96-102. https:// doi.org/10.4314/ejhd.v24i2.62957

Onoya, D., Zuma, K., Zungu, N., Shisana, O., \& Mehlomakhulu, V. (2015). Determinants of multiple sexual partnerships in South Africa. Journal of Public Health (United Kingdom), 37(1), 97-106. https:// doi.org/10.1093/pubmed/fdu010

Oppong Asante, K. (2013). HIVIAIDS knowledge and uptake of HIV counselling and testing among undergraduate private university students in Accra, Ghana. Reproductive Health, 10(1), 17. https:// doi.org/10.1186/1742-4755-10-17

Ouellette, J. \& Wood, W. (1998). Habit and intention in everyday life: The multiple processes by which past behavior predicts future behavior. Psychological Bulletin, 124(1), 54-74. https://doi. org/10.1037/0033-2909.124.1.54

Pattij, T., Wiskerke, J., \& Schoffelmeer, A. N. M. (2008). Cannabinoid modulation of executive functions. European Journal of Pharmacology, 585(2-3), 458-463. https://doi.org/10.1016/j. ejphar.2008.02.099

Rehm, J., Shield, K. D., Joharchi, N., \& Shuper, P. (2012). Alcohol consumption and the intention to engage in unprotected sex: Systematic review and meta-analysis of experimental studies. Addiction (Abingdon, England), 107(1), 51-59. https://doi. org/10.1111/j.1360-0443.2011.03621.x

Republic of South Africa. (1996). National Youth Commission Act (Act 19 of 1996). Pretoria.

Saal, W. \& Kagee, A. (2011). The applicability of the theory of planned behaviour in predicting adherence to ART among a South African sample. Journal of Health Psychology, 17(3), 362-370. https://doi. org/10.1177/1359105311416875

Scott-Sheldon, L. A. J., Carey, M. P., Carey, K. B., Cain, D., Simbayi, L. C., Mehlomakhulu, V., \& Kalichman, S. C. (2013). HIV testing is associated with increased knowledge and reductions in sexual risk behaviours among men in Cape Town, South Africa. African Journal of Aids Research, 12(4), 195-201. https://doi.org/10.2989/1608590 6.2013.863219

Sharma, M., Ying, R., Tarr, G., \& Barnabas, R. (2015). Systematic review and meta-analysis of community and facility-based HIV testing to address linkage to care gaps in sub-Saharan Africa. Nature, 528(7580), S77-85. https://doi.org/10.1038/nature16044

Sifunda, S., Reddy, P. S., Braithwaite, R., Stephens, T., Bhengu, S., Ruiter, R. a C., \& van den Borne, B. (2008). The effectiveness of a peer-led HIVIAIDS and STI health education intervention for prison inmates in South Africa. Health Education \& Behavior, 35(4), 494-508. https://doi.org/10.1177/1090198106294894

Sifunda, S., Reddy, P. S., Braithwaite, R., Stephens, T., Ruiter, R. a C., \& van den Borne, B. (2006). Access point analysis on the state of health care services in South African prisons: A qualitative exploration of correctional health care workers' and inmates' perspectives in Kwazulu-Natal and Mpumalanga. Social Science \& Medicine, 63, 2301-2309. https://doi.org/10.1016/j. socscimed.2006.06.010 
Sileo, K. M., Fielding-Miller, R., Dworkin, S. L., \& Fleming, P. J. (2018). What role do masculine norms play in men's HIV testing in sub-Saharan Africa?: A scoping review. AIDS and Behavior, 22(8), 2468-2479. https://doi.org/10.1007/s10461-018-2160-z

Simbayi, L. C., Zuma, K., Zungu, N., Moyo, S., Marinda, E., Jooste, S., Mabaso, M., Ramlagan, S., North, A., Van Zyl, J., Mohlabane, N., Dietrich, C., Naidoo, I., \& Team, S. V. (2019). South African National HIV Prevalence, Incidence, Behaviour and Communication Survey, 2017. HSRC PRESS. http://www.unaids.org/epi/2005/doc/ report_pdf.asp

Statistics South Africa. (2016). General Household Survey 2016. https://www.statssa.gov.za/publications/P0318/P03182016.pdf

Suthar, A. B., Ford, N., Bachanas, P. J., Wong, V. J., Rajan, J. S., Saltzman, A. K., Ajose, O., Fakoya, A. O., Granich, R. M., Negussie, E. K., \& Baggaley, R. C. (2013). Towards universal voluntary HIV testing and counselling: A systematic review and meta-analysis of community-based approaches. PLoS Medicine, 10(8). https://doi. org/10.1371/journal.pmed.1001496

UNAIDS. (2014). UNAIDS: The Gap Report. https://www.hivlawandpolicy.org/resources/ gap-report-joint-united-nations-programme-hivaids-unaids-2014

UNAIDS. (2018). Country factsheets South Africa| 2018. https:// aidsinfo.unaids.org $/ \% 0 \mathrm{D}$

UNAIDS. (2019) UNAIDS Data 2019. https://www.unaids.org/sites/ default/files/media_asset/2019-UNAIDS-data_en.pdf_aidsinfo. unaids.org

United Nations. (2005). World Youth Report 2005: Young people today and in 2015. New York.
Van Heerden, A., Msweli, S., \& Van Rooyen, H. (2015). "Men don't want things to be seen or known about them": A mixed-methods study to locate men in a home based counselling and testing programme in KwaZulu-Natal, South Africa. African Journal of AIDS Research, 14(4), 353-359. https://doi.org/10.2989/16085906.2015 .1121881

Vigen, M. \& Mazur-Stommen, S. (2012). Reaching the "high-hanging fruit" through behavior change: How community-based social marketing puts energy savings within reach. American Council for an Energy Efficient Economy. http://pt.energytaxincentives.org/files/ pdf/white-paper/high-hanging-fruit-cbsm.pdf

Weihs, M. \& Meyer-Weitz, A. (2016). Barriers to workplace HIV testing in South Africa: A systematic review of the literature. AIDS Care, 28, 495-499. https://doi.org/10.1080/09540121.2015.1109586

Witzel, T. C., Lora, W., Lees, S., \& Desmond, N. (2017). Uptake contexts and perceived impacts of HIV testing and counselling among adults in East and Southern Africa: A meta-ethnographic review. PLoS ONE, 12(2), 1-16. https://doi.org/10.1371/journal. pone. 0170588

World Health Organization (WHO). (2016). Consolidated guidelines on the use of antiretroviral drugs for treating and preventing HIV infection: recommendations for a public health approach.

Zhang, Q., Fu, Y. S., Liu, X. M., Ding, Z. Q., Li, M. Q., \& Fan, Y. G. (2020). HIV prevalence and factors influencing the uptake of voluntary HIV counseling and testing among older clients of female sex workers in Liuzhou and Fuyang cities, China, 2016-2017: A cross-sectional study. BioMed Research International, 2020, 8. https://doi.org/10.1155/2020/9634328 